\title{
Dynamic Tests: Passenger Car vs. Child Pedestrian
}

\author{
Z. Schejbalová* \& A. Kvášová \\ Faculty of Transportation Sciences, Czech Technical University in Prague, Prague, Czech Republic \\ *Corresponding author: schejbalova@fd.cvut.cz
}

\author{
Z. Marek \\ Police Academy of Czech Republic, Prague, Czech Republic
}

DOI: 10.2478/v10158-010-0025-x

\begin{abstract}
The Department of Forensic Experts in Transportation at the Faculty of Transportation Sciences performed a second set of dynamic passive safety tests on a passenger car (M1 category - Škoda Octavia II) in a child pedestrian collision. Initial and test conditions were similar to those that were made in the first set of tests in September 2009 (Škoda Roomster). Deformations of contact zones on the frontal vehicle surface were analyzed by 3D scanning technology (3D handy scanner). Head, thorax and pelvic resultant acceleration, acceleration of knee joint in sagittal direction and the contact force on the femoral structure of the dummy (P6 dummy, 1.17m; 22kg) were measured. The aim of these tests is not only to provide a detailed description of pedestrian kinematics and a comparison of primary and secondary impact seriousness, but also to provide a data source for advanced mathematical modeling.
\end{abstract}

KEY WORDS: Primary and secondary impact, child pedestrian, instrumentation, injury criteria.

\section{INTRODUCTION}

Pedestrian safety is nowadays a very important criterion for vehicle safety evaluation. Vehicle certification standards are based on vehicle frontal part testing with impactors which represent the certain body parts of an adult pedestrian. The risk of impact consequences for children is only tested through a head impactor test.

The Faculty of Transportation Sciences performed a second set of three dynamic passive safety tests for a passenger car (category M1 - Škoda Octavia II) in a child pedestrian collision. The tests were executed at different impact speeds (10, 20, $30 \mathrm{kmph}$ ), analogous to the first set of tests carried out in September 2009 with a Škoda Roomster. It was clear from the first set of tests that several body parts are more threatened than the head during a primary impact with a vehicle. The resultant acceleration of the head, thorax and pelvis were measured using child dummy P6. The dummy was modified because of the demand for a higher number of measuring areas than in the case of the original P6 dummy, which is intended for child restraints testing. The left upper leg was equipped with two straingauge half bridges on the femoral skeleton for contact force measurement. One uniaxial accelerometer was installed in the knee area for the measurement of acceleration 
in the sagittal direction. Deformations of contact zones on the frontal vehicle surface were analyzed using 3D scanning technology.

Initial and test conditions were similar to those used for tests in 2009. Acceleration measurement was made using new equipment. The aim of this second set of tests was to identify and verify critical contact zones on the vehicle frontal part regarding the pelvic and femoral part of the dummy, and to compare the results with the previous set of tests carried out with the Škoda Roomster.

\section{EXPERIMENT}

\subsection{Conditions}

With respect to the technical specifications and the possibility of comparability with previous measurements, the following initial conditions were formulated:

a) collision of passenger car (M1 category),

b) P6 dummy, (6 years; $1.17 \mathrm{~m} ; 22 \mathrm{~kg}$ ) which was adapted for the test - mentioned above (Note: There is no child dummy which is specified for full-scale pedestrian vehicle crash tests).

c) dummy position: the dummy was facing the approaching vehicle, heel standing in the longitudinal axis of the vehicle (see Figure 1),

d) proposed collision speeds: 10, 20, $30 \mathrm{kmph}$,

e) vehicle is starting to break at the moment of crash contact.
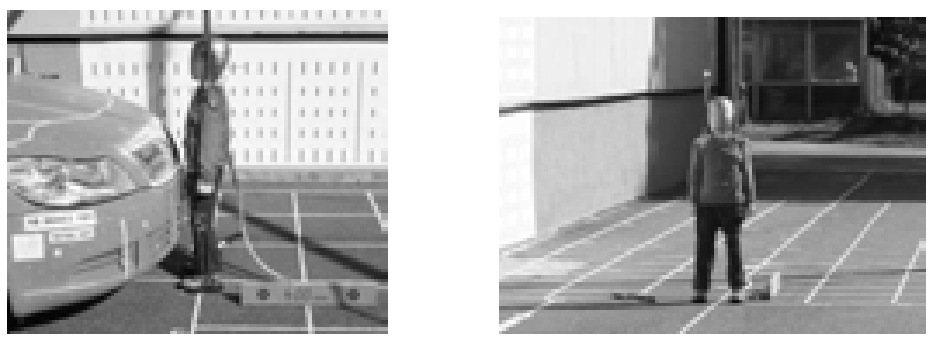

Figure 1: Initial dummy possition.

Measured quantities:

- $\quad$ a real vehicle speed, vehicle acceleration (3D),

- acceleration time flow of dummy (according to dummy instrumentation),

- contact force time flow in the femur,

- high speed video recording,

- dimensional characteristics of the process (initial and final location of colliding object),

- 3D scanning of contact zones after collision and car damage.

Dummy instrumentation (see Figure 2):

- head: 3-axis accelerometer, directions x,y,z, 1000 g range,

- thorax: 3-axis accelerometer, directions $\mathrm{x}, \mathrm{y}, \mathrm{z}, 1000 \mathrm{~g}$ range,

- pelvic region: 3-axis accelerometer, directions $\mathrm{x}, \mathrm{y}, \mathrm{z}, 500 \mathrm{~g}$ range,

- knee joint: 1-axis accelerometer, direction x, 500 g range,

- upper leg: femoral skeleton - two strain-gauge halfbridges, uniaxial state of stress. 


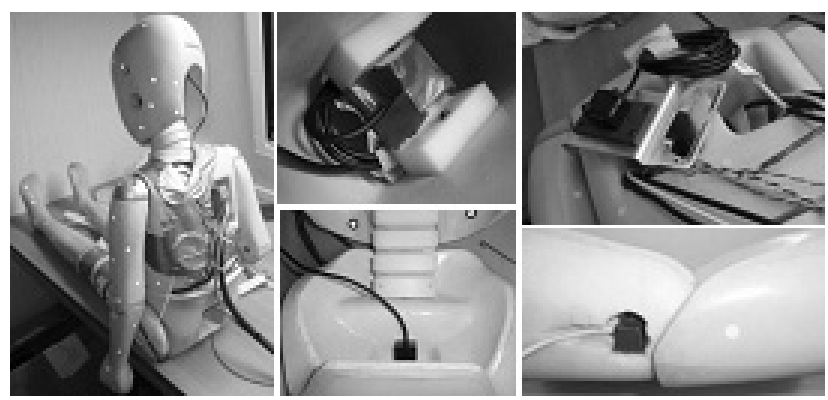

Figure 2: Dummy instrumentation.

Passenger car Škoda Octavia II, 1.4 MPI:

- maximum power: $\quad 59 \mathrm{~kW}$

- total displacement: $1390 \mathrm{~cm}^{3}$

- curb weight: $1255 \mathrm{~kg}$

- the car was equipped with an antireflection coating and impact zones on the bonnet due to 2003/102/EC directive were marked.

\section{TIME COURSE OF THE EXPERIMENT}

Three tests were made at a real impact speed $12.2 \mathrm{kmph}$ (test No. 101), $22.4 \mathrm{kmph}$ (test No. 201) and 30.6 kmph (test No. 301).

The following sequence demonstrates the time course of the test No. 301, impact speed $30.6 \mathrm{kmph}$.

Time of the first contact of the dummy with the vehicle: $\mathrm{t}_{\mathrm{s} 301}=3 \mathrm{~ms}$.

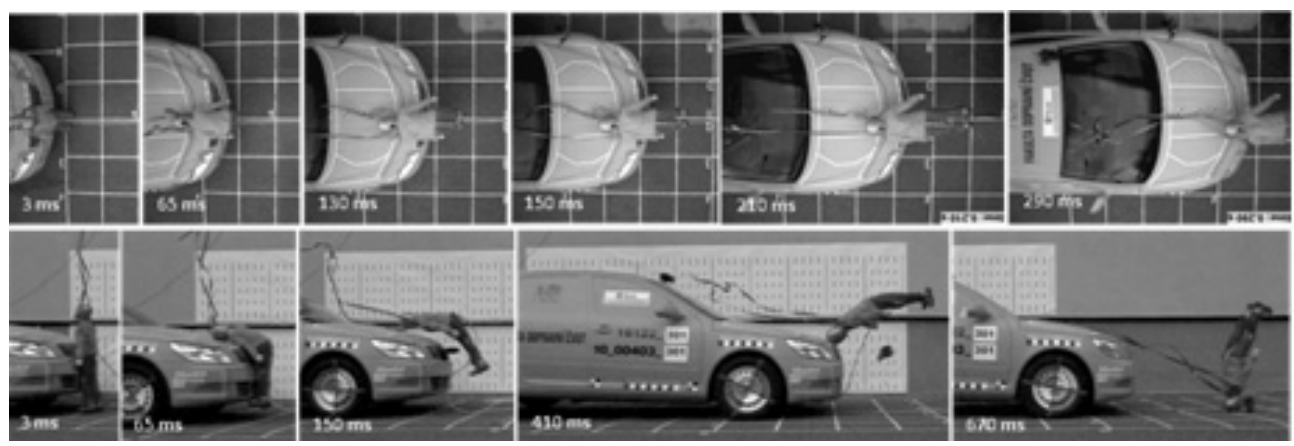

Figure 3a: Time course of the test No. 301. 


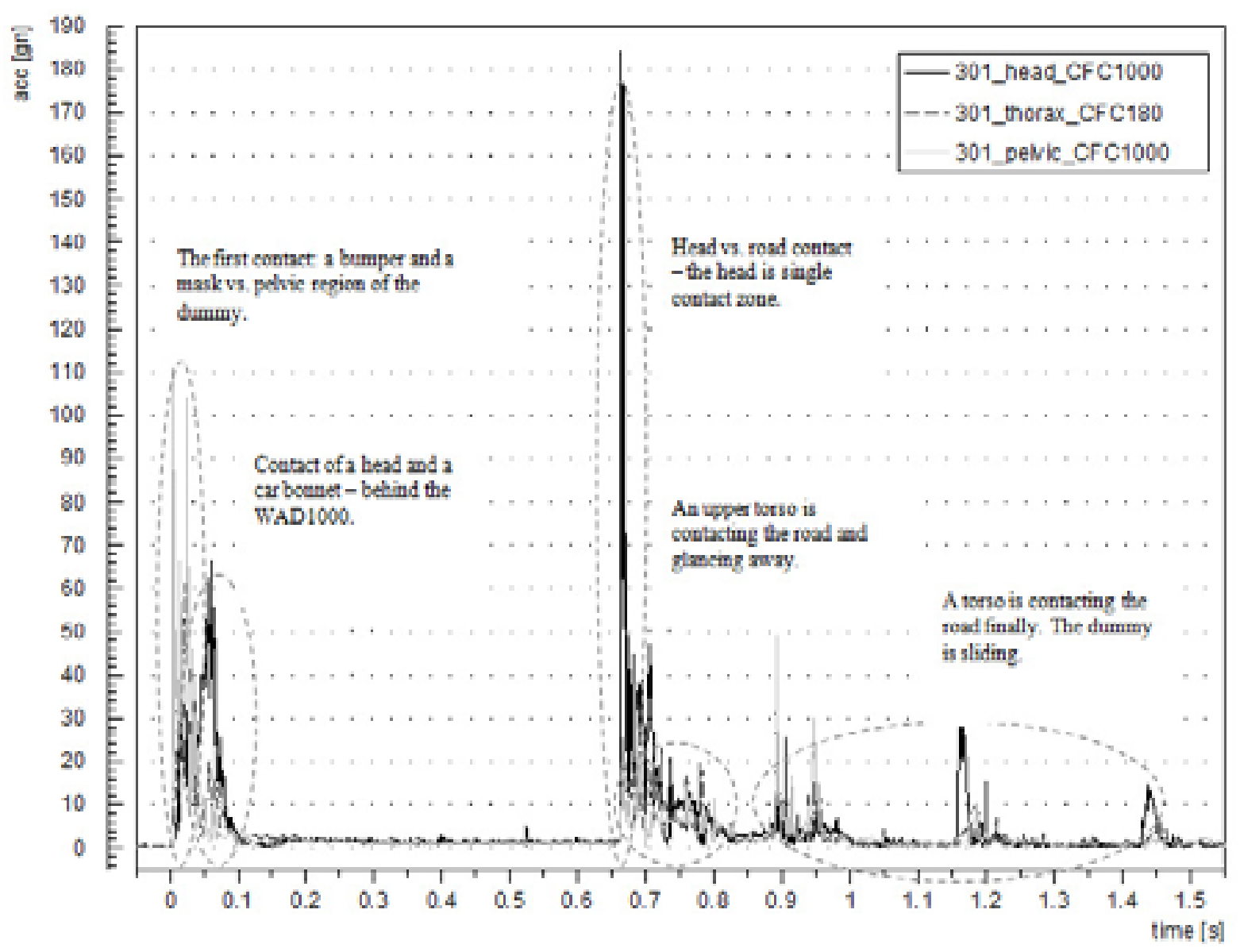

Figure 3b: Time course of the test No. 301.

\section{RESULTS}

4.1 Biomechanical criteria values

\section{Injury criteria - head: HPC and 3ms}

Head performance criterion is defined by the following formula:

$$
H P C=\left[\frac{1}{t_{2}-t_{1}} \int_{t_{1}}^{t_{2}} a \cdot d t\right]^{2,5}\left(t_{2}-t_{1}\right) \text {, where }
$$

$\mathrm{a}=$ resultant acceleration in $\mathrm{g}, \mathrm{t}_{1} \mathrm{a} \mathrm{t}_{2}=$ time points, which determines the beginning and end of the time interval, where HPC value is maximum. HPC limit value is 1000. According to the US standard FMVSS 208 "Occupant crash protection" $\mathrm{HPC}_{15}$ limit value in the case of a 6-year-old child reaches 700 .

HPC measured values 3ms criterion is applicable, not only to head performance, but also to other body segments. Limit value for head is $80 \mathrm{~g}$. Criterion interpretation: Acceleration higher than $80 \mathrm{~g}$ must not act longer than 3ms.

According to the US standard FMVSS 208 "Occupant crash protection“ HPC15 limit value in the case of 6 -year-old child reaches $60 \mathrm{~g}$. $3 \mathrm{~ms}$ measured values (see Table 1 ). 
Table 1: Head performance criterion (HPC) and 3ms criterion.

\begin{tabular}{|c|c|c|c|c|c|c|c|c|c|}
\hline \multirow{2}{*}{ test no: } & \multirow{2}{*}{ velocity } & \multicolumn{2}{|c|}{ Primary impact } & \multicolumn{2}{c|}{ Secondary impact } & \multicolumn{2}{c|}{ Primary impact } & \multicolumn{2}{c|}{ Secondary impact } \\
\cline { 2 - 10 } & & \multicolumn{2}{|c|}{ HPC $_{15}$} & \multicolumn{2}{|c|}{ HPC $_{15}$} & \multicolumn{2}{c|}{ a3ms } & \multicolumn{2}{c|}{ a3ms } \\
\cline { 2 - 10 } & {$[\mathrm{kmph}]$} & {$[-]$} & limit & {$[-]$} & limit & {$[\mathrm{g}]$} & limit & {$[\mathrm{g}]$} & limit \\
\hline 101 & 12.2 & $\mathbf{5 8 . 2}$ & $1000 / 700$ & $\mathbf{1 3 5 . 6}$ & $1000 / 700$ & $\mathbf{3 3 . 7}$ & $80 / 60$ & $\mathbf{5 2 . 8}$ & $80 / 60$ \\
\hline 201 & 22.4 & $\mathbf{5 8 . 3}$ & $1000 / 700$ & $\mathbf{5 5 4 . 8}$ & $1000 / 700$ & $\mathbf{2 6 . 1}$ & $80 / 60$ & $\mathbf{4 9 . 7}$ & $80 / 60$ \\
\hline 301 & 30.6 & $\mathbf{2 5 1 . 3}$ & $1000 / 700$ & $\mathbf{8 6 2 . 7}$ & $1000 / 700$ & $\mathbf{4 6 . 6}$ & $80 / 60$ & $\mathbf{8 8 . 7}$ & $80 / 60$ \\
\hline
\end{tabular}

\section{3ms injury criteria - thorax}

Limit value of this criterion in the case of the thorax is $60 \mathrm{~g}$. According to standard ECE 44 "Child restraints systems" the limit value in the case of a 6-year-old child reaches $55 \mathrm{~g}$. Measured values (see Table. 2):

Table 2: 3ms criterion - thorax.

\begin{tabular}{|c|c|c|c|c|c|}
\hline \multirow{2}{*}{ test no: } & \multirow{2}{*}{ velocity } & \multicolumn{2}{|c|}{ Primary impact } & \multicolumn{2}{c|}{ Secondary impact } \\
\cline { 2 - 6 } & & \multicolumn{2}{|c|}{ a3ms } & \multicolumn{2}{c|}{ a3ms } \\
\cline { 2 - 6 } & {$[\mathrm{kmph}]$} & {$[\mathrm{g}]$} & limit & {$[\mathrm{g}]$} & limit \\
\hline 101 & 12.2 & $\mathbf{1 3 . 6}$ & $60 / 55$ & $\mathbf{1 9 . 3}$ & $60 / 55$ \\
\hline 201 & 22.4 & $\mathbf{3 8 . 9}$ & $60 / 55$ & $\mathbf{2 1 . 7}$ & $60 / 55$ \\
\hline 301 & 30.6 & $\mathbf{5 0 . 9}$ & $60 / 55$ & $\mathbf{2 2 . 9}$ & $60 / 55$ \\
\hline
\end{tabular}

$a_{\max }$ injury criteria - pelvic

Maximum acceleration value must not exceed $130 \mathrm{~g}$ (see Table 3).

Table 3: 3ms criterion - pelvic.

\begin{tabular}{|c|c|c|c|c|c|}
\hline \multirow{2}{*}{ test no: } & \multirow{2}{*}{ velocity } & \multicolumn{2}{|c|}{ Primary impact } & \multicolumn{2}{c|}{ Secondary impact } \\
\cline { 2 - 6 } & & \multicolumn{2}{|c|}{$\mathrm{a}_{\max }$} & \multicolumn{2}{|c|}{$\mathrm{a}_{\max }$} \\
\cline { 2 - 6 } & {$[\mathrm{kmph}]$} & {$[\mathrm{g}]$} & limit & {$[\mathrm{g}]$} & limit \\
\hline 101 & 12.2 & $\mathbf{3 7 . 1}$ & 130 & $\mathbf{3 6 . 6}$ & 130 \\
\hline 201 & 22.4 & $\mathbf{6 5 . 9}$ & 130 & $\mathbf{4 4 . 2}$ & 130 \\
\hline 301 & 30.6 & $\mathbf{1 1 1 . 4}$ & 130 & $\mathbf{3 9 . 1}$ & 130 \\
\hline
\end{tabular}

\section{Femur injury criteria - contact force}

Bending femur tolerance is not strictly defined. In the case of an adult femur the following bending limits are frequently published: $1.5 \mathrm{kN}$ to $4 \mathrm{kN}$. Levine (2002) published a bending limit value till rupture of $3.92 \mathrm{kN}$ for men and $2.58 \mathrm{kN}$ for women. Yamada (1970) published the maximum bending limit till specimen rupture in relation to donor's age. In the group from 20 to 39 years the limit is cca $2.8 \mathrm{kN}$ in case of $260 \mathrm{~mm}^{2}$ femur cortical bone crosssectional area and bending strength $212 \mathrm{~N} / \mathrm{mm}^{2}$. In the children group of around 6 years Yamada published the same level of bending strength, the femur has a higher level of plasticity and is able to absorb more energy till rupture, the cross-sectional area of the cortical bone is smaller. For measured values see Figure 4 and Table 4.

Table 4: Maximum contact force - femur.

\begin{tabular}{|c|c|c|}
\hline \multirow{2}{*}{ test no: } & \multicolumn{2}{|c|}{ Primary impact } \\
\cline { 2 - 3 } & \multicolumn{2}{|c|}{$\mathrm{F}_{\max }$} \\
\cline { 2 - 3 } & {$[\mathrm{N}]$} & $\mathrm{t}[\mathrm{ms}]$ \\
\hline 101 & $\mathbf{8 7 7}$ & 55 \\
\hline 201 & $\mathbf{2 4 9 7}$ & 35.5 \\
\hline 301 & $\mathbf{3 4 1 8}$ & 26.2 \\
\hline
\end{tabular}




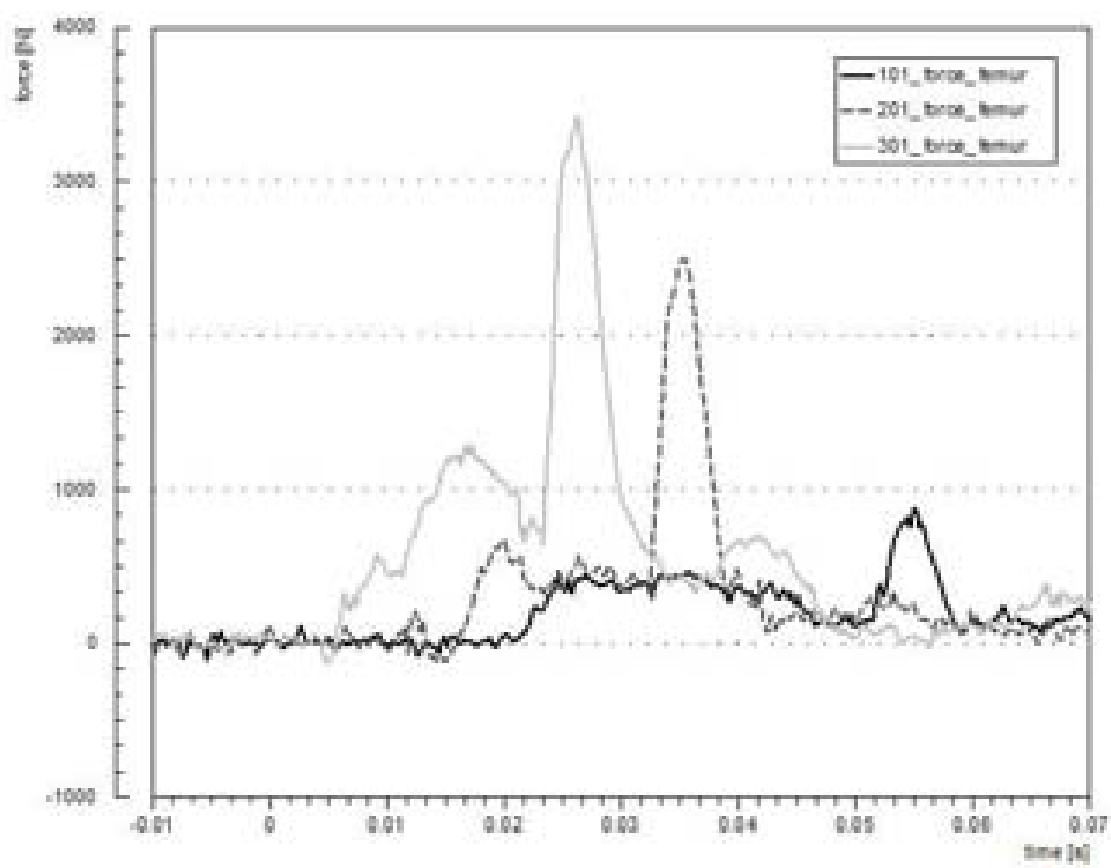

Figure 4: Femur contact force time course.

\section{Knee acceleration}

Maximum acceleration value must not exceed $170 \mathrm{~g}$. Measured values are in Table 5.

Table 5: Maximum knee acceleration in $\mathrm{x}$ direction.

\begin{tabular}{|c|c|c|c|c|}
\hline \multirow{2}{*}{ test no: } & \multicolumn{2}{|c|}{ Primary impact } & \multicolumn{2}{c|}{ Secondary impact } \\
\cline { 2 - 5 } & \multicolumn{2}{|c|}{$\mathrm{a}_{\max }$} & \multicolumn{2}{c|}{$\mathrm{a}_{\max }$} \\
\cline { 2 - 5 } & {$[\mathrm{g}]$} & limit & {$[\mathrm{g}]$} & limit \\
\hline 101 & $\mathbf{7 4 . 6}$ & 170 & $\mathbf{5 0 . 5}$ & 170 \\
\hline 201 & 186.8 & 170 & $\mathbf{9 6}$ & 170 \\
\hline 301 & $\mathbf{2 1 0 . 4}$ & 170 & $\mathbf{5 4 . 2}$ & 170 \\
\hline
\end{tabular}

\subsection{D scanning - 3D data digitalization}

3D scanning is a process of data digitalization; the goal is to express the real object in a virtual (mathematical) way. This method of digitalization is able to record space or solids effectively.

The result of 3D digitalization is "a point cloud" where the position of every single point is detected by a 3D scanner. This type of application in connection with the formulated task allows the recording of damage to a car body after a crash test.

Method requirements: mobility of device, limited time for scanning (max. 15 minutes for one scanning series), scanning accuracy (in $0.01 \mathrm{~mm}$ ), reliability of the device, data quality, non-contact scanning, outdoor performance, variable lightning conditions, availability of scanned object position change, scanning interruption, "easy" data processing, real time result visualization (data verification).

With respect to the facts mentioned above, the Handyscan type MAXScan from CreaForm was chosen for this application. The advantage of this type of scanner is the possibility of a relative motion of the scanner and scanned object. The scanner identifies position markings on the scanned object and two cameras record the laser intersection, which is projected on the object.

For the car body deformation scanning, parts on the vehicle front (bumper, hood, fenders, front grill) were covered with reflex targets. The original vehicle frontal parts were fitted 
appropriately and scanned because of the following comparison with those that were damaged by the crash test. 3D analysis is based on 3D surfaces comparison.

The results from the test 101/201/301 (12.2 kmph/22.4 kmph/30.6 kmph) show that the dummy head impact caused plastic deformation of the hood of $13.2 \mathrm{~mm} / 23.7 \mathrm{~mm} / 20 \mathrm{~mm}$ (depth), the rear central part of the hood was deflected in test 101 on average by $1.5 \mathrm{~mm}$. The dummy head's contact point is revealed by the dark area on the deformation map, the lifted area of the hood in test 201/301 reached a maximum of $6.7 \mathrm{~mm} / 8.8 \mathrm{~mm}$.

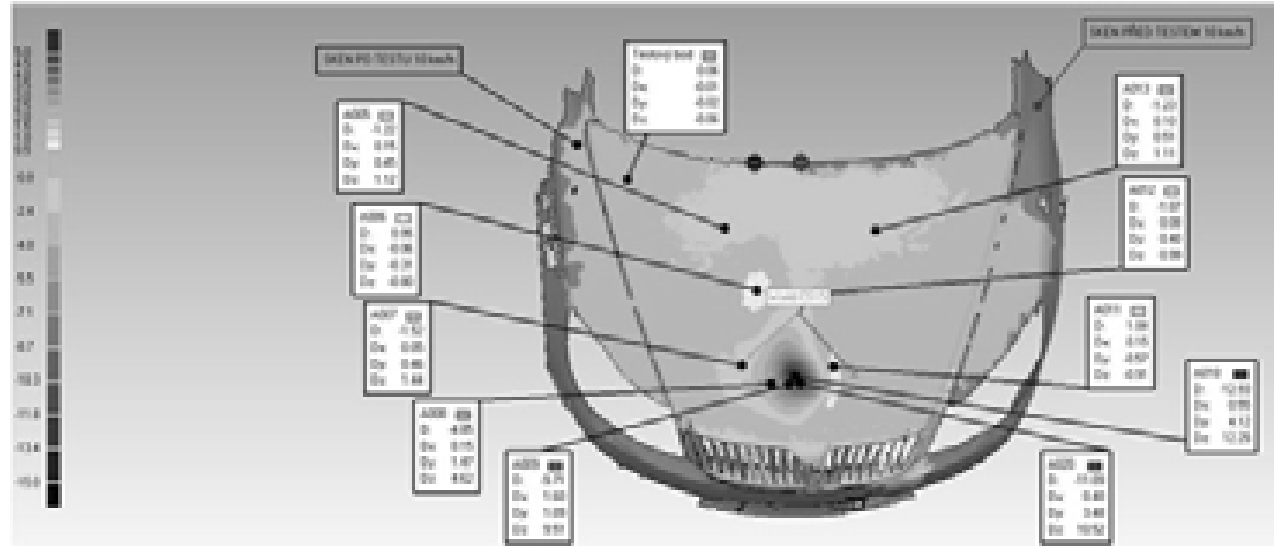

Figure 5: 3D analysis and deformation map for the test 101, $12.2 \mathrm{kmph}$.

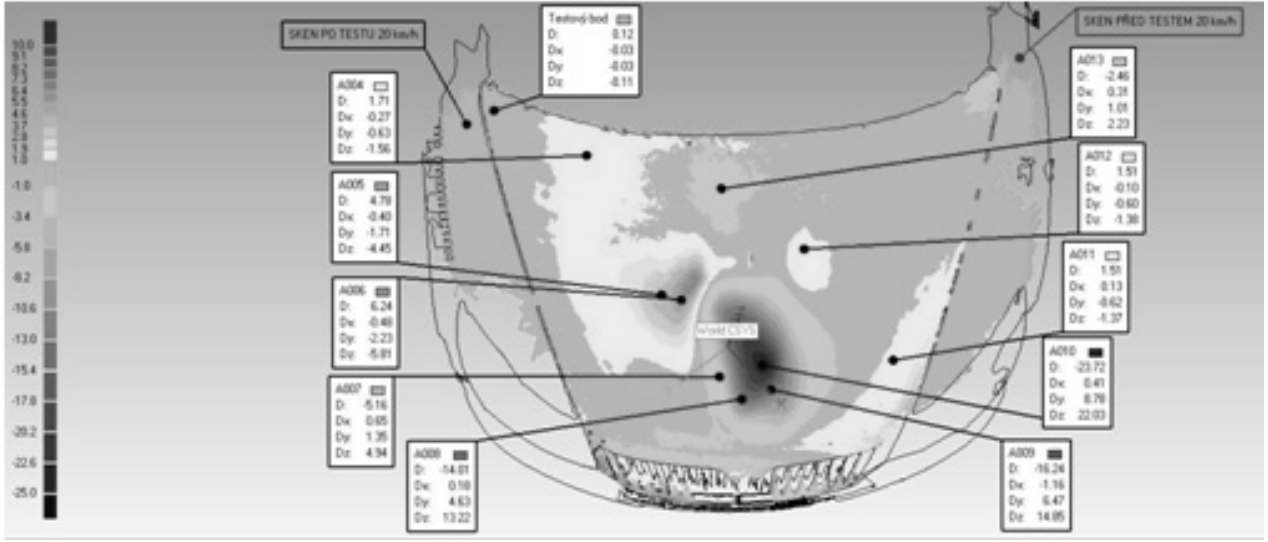

Figure 6: 3D analysis and deformation map for the test 201, $22.4 \mathrm{kmph}$.

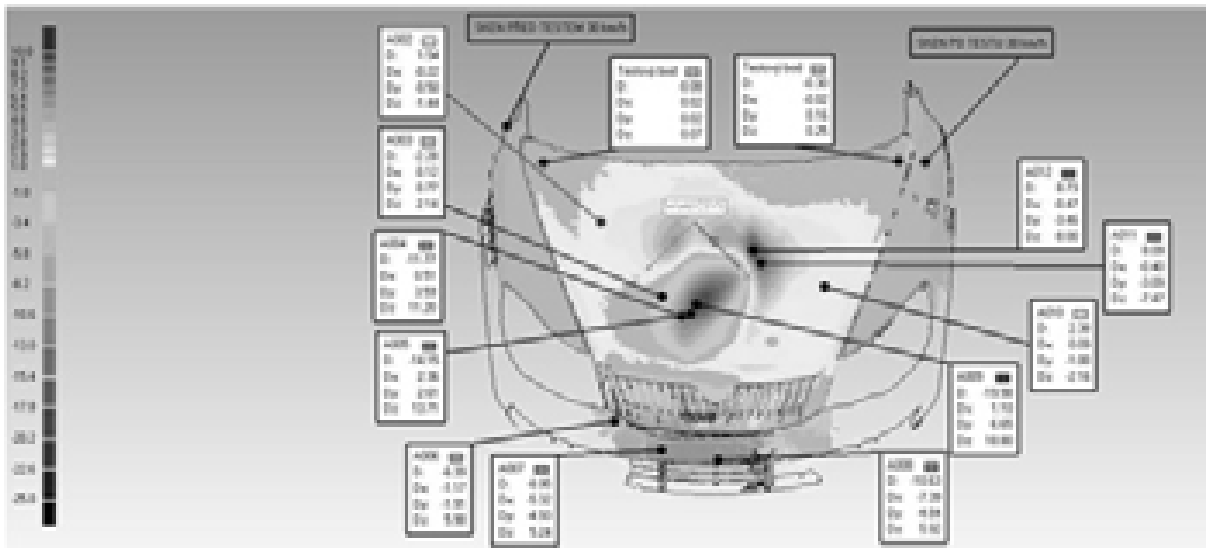

Figure 7: 3D analysis and deformation map for the test 301, $30.6 \mathrm{kmph}$. 


\section{DISCUSSION}

\subsection{Head injuries}

Neither Head Performance Criteria (HPC), nor 3ms injury criteria limit value was exceeded in the primary head impact for all performed tests. The head contacted with the car bonnet behind the WAD1000 line.

The values of the biomechanical criteria are several times larger for the secondary impact than for the primary one. The limit value for the secondary impact was only exceeded in the case of test No. 301 (30.6 kmph), the 3ms criteria was in this case exceeded by over $10 \%$. According to the US standards (FMVSS 208 "Occupant crash protection"), the value of HPC15 also exceeded the defined limit (limit 700) for a 6-year-old child.

Based on the test and video analysis, the analysis of a secondary contact with the road surface, it is obvious that neither the HPC value nor the 3ms criteria objectively represent the seriousness of the secondary impact. The reason is probably a mechanism of dominating flexion and extension motion in neck spine and the head skidding on the road surface. This conclusion corresponds to previous experiments made in 2009.

\subsection{Thorax injuries}

The limit value of 3ms criteria for a 6-year-old child's thorax (55 g according to the EHK 44) was not exceeded in any executed test. This value is close to the limit in test No. 301 for primary impact. For the secondary impact, there is no critical acceleration because of the kinematics of the pedestrian after the collision. The secondary contact was taken mostly via head and neck.

\subsection{Pelvic area injuries}

The maximum acceleration limit $a_{\max } 130 \mathrm{~g}$ was not exceeded in any executed test for the primary or secondary impact. The pelvic area is a point of first contact with the car's frontend, it is clearly seen from the graphic representation of acceleration and video records made by a high speed (HS) camera. The highest acceleration values for the pelvic area were measured at primary contact. There is a presumption of contusion of abdominal organs and the risk of pelvic fracture (symphysis pubic). The pelvic and knee areas were the most loaded parts of the body within the experimental series.

\subsection{Knee injuries}

The limit value of maximum acceleration for the knee (170 g) was exceeded in test No. 201 and 301 (primary impact). Injury of the knee joint or a fracture of a crus (on epiphysis or metaphysis) is highly probable.

\subsection{Femur contact force}

The limit value of maximum contact force on the femoral skeleton is not exactly defined. On the basis of research, we can say that the average biomechanical limit for contact force was exceeded at primary impact in test No. 301. In this case a femur fracture can be predicted. The impact force on the femoral skeleton was calculated from axial strain with a knowledge of material properties. 


\subsection{Secondary impact remarks}

HPC seems to be an indicator of secondary impact seriousness regarding the fact that in all tests it reached higher values than in primary contact with the vehicle's frontal part. An interesting observation is that in the case of other body parts the results were inverse the primary impact was the one with more serious consequences regarding biomechanical criteria values calculated for dynamical impacts of certain body parts in direct interaction with a vehicle's frontal part.

\subsection{Comparison with previous set of test with Škoda Roomster}

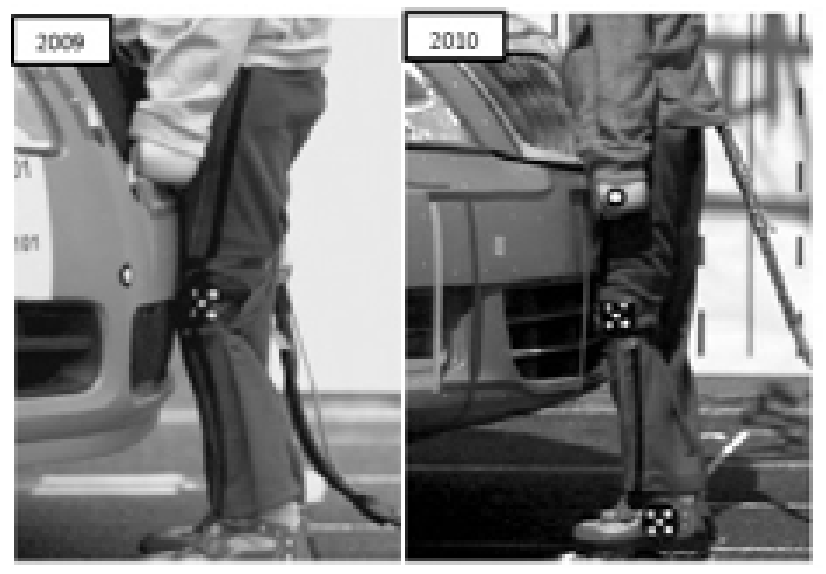

Figure 8: Primary contact with the vehicle’s frontal part (2009 - Škoda Roomster, 2010 Škoda Octavia II.)

Head: smoother shape of the primary collision acceleration curve in the Škoda Roomster mainly under lower speed of collision, lower HPC and 3ms values.

Thorax: smoother shape of the primary collision acceleration curve in the Škoda Roomster under lower speed of collision, lower values of acceleration.

Pelvic: higher maximum acceleration value in the primary collision in the Škoda Octavia II mainly under higher speed of collision (pelvis was the initial contact zone in the Škoda Octavia II test - see Figure 8).

Femoral skeleton: slightly higher maximum contact force value in the Škoda Roomster test (the femoral part with the knee joint was the initial contact zone in the Škoda Roomster test see Figure 8).

\section{CONCLUSION}

The CTU in Prague, Faculty of Transportation Sciences, performed a second set of dynamic passive safety tests on a passenger car (Škoda Octavia II) collision with a P6 dummy. The specific conclusions and findings are in the discussion part of this paper.

The most significant finding is that in the primary collision the pelvic and femoral part are the most threatened parts of a child pedestrian's body when in collision with a vehicle. 
There are slight differences in acceleration or force loading regarding the vehicle's frontal shape. Nevertheless, from the results it is obvious that it is necessary to focus on the action of force to the upper and lower leg at primary contact and the necessity of force moment and acceleration measurement on the neck of the dummy - for the reasons of analysis of secondary impact seriousness. It is a very complex issue which requires further deep research; for example, to choose the factors that can significantly influence the post-crash kinematics and perform numerical analysis of a response to factors variation. According to the presented research it will be desirable to propose Regulation No 78/2009 amendment with respect to child impactor testing distribution (pelvic and legform test).

Although primary impact consequences can be positively affected by a vehicle's construction, the secondary ones can not be influenced significantly and still represent a critical danger for a pedestrian's head which can be eliminated only by prevention measures.

\section{ACKNOWLEDGEMENT}

This contribution is supported by MSM6840770043, Škoda Auto, a.s., TÜV SÜD Czech s.r.o., A.L.C.Z. a.s., Solid Vision s.r.o.

\section{REFERENCES}

Berg F. A., Egelhaaf M., Bakker J., Burkle H., Herrmann R., Scheerer J.: Pedestrian Protection in Europe -The Potential of Car Design and Impact Testing, DEKRA Automobil GmbH, Accident Research and DaimlerChrysler AG, Accident Research http://www.unece.org/trans/doc/2002/wp29grsp/inf-gr-ps-13e.pdf

Nahum A. M., Melvin J.,W.: Accidental Injury - Biomechanics and prevention, ISBN 0-38798820-3, Springer, 2002

DIRECTIVE 2003/102/EC OF THE EUROPEAN PARLIAMENT AND OF THE COUNCIL of 17 November 2003 relating to the protection of pedestrians and other vulnerable road users before and in the event of a collision with a motor vehicle and amending Council Directive 70/156/EEC

\section{IHRA INJURY BREAKDOWN}

http://www.unece.org/trans/doc/2005/wp29grsp/ps-140e.pdf

IHRA/PS-WG PEDESTRIAN TRAFFIC ACCIDENT DATA

http://www.unece.org/trans/doc/2003/wp29grsp/ps-31.doc

Legislation EHK44 - Child restraints systems

Legislation FMVSS 208 - “Occupant crash protection”

REGULATION (EC) No 78/2009 OF THE EUROPEAN PARLIAMENT AND OF THE COUNCIL of 14 January 2009 on the type-approval of motor vehicles with regard to the protection of pedestrians and other vulnerable road users, amending Directive 2007/46/EC and repealing Directives 2003/102/EC and 2005/66/EC 